${ }^{1}$ Médico-Cirujano, Profesor Asociado de la Facultad de Medicina de la Universidad de Chile. Santiago, Chile. ${ }^{a}$ Adscrito al Instituto de Salud Poblacional (Escuela de Salud Pública) y al programa de Políticas y Gestión del mismo.

Recibido el 4 de mayo de 2020, aceptado el 28 de septiembre de 2020.

Correspondencia a: Dr. Marcos Vergara Escuela de Salud Pública Independencia 939, Independencia. Santiago, Chile. mvergara@med.uchile.cl

\section{Instituciones y licencias Médicas en Chile}

\author{
MARCOS VERGARA ${ }^{1, a}$
}

\section{Sick leaves in Chile}

In Chile, sick leaves serve the extra purpose of filling social protection gaps. Therefore, in practice, their operation range extends beyond health care regulations. In our institutional framework, sick leaves are used to fill social protection gaps and to accomplish an assortment of other purposes that justify an absence from work.

(Rev Med Chile 2020; 148: 1350-1356)

Key words: Chile; Public Policy: Sick Leave.

\section{El Problema}

1 1 soporte de la norma y la propia normativa de licencias médicas en Chile ofrecen un panorama diverso e irregular, que resulta de años de remendados adaptativos, al punto que la responsabilidad de control recae en varias entidades que lo asumen parcialmente y que realizan una administración frágil y expuesta al abuso y al fraude.

Producto de lo anterior, el sistema opera como seguro de último término frente a carencias globales de protección social y se utiliza para suplir necesidades variadas que tienen las personas.

Por una parte, compensa los tiempos de espera asociados a tramitación de pensiones de invalidez, compensa limitaciones del listado de enfermedades ocupacionales y compensa limitaciones del seguro de cesantía. Al mismo tiempo, el sistema opera con laxitud, transformado en medio para justificar ausencias laborales sin enfermedad o para prolongar el reposo más allá de lo necesario.

Tal como en otros asuntos, hay limitaciones o constreñimientos en el entorno social y político del problema que no han sido vistos al momento de ponerlo en debate. Es posible postular que, por encima de quienes administran el sistema e incluyéndoles, existe un marco institucional, en su sentido amplio -"reglas del juego"-, que determina el comportamiento de los interesados.
No es el caso adentrarnos en un análisis pormenorizado de los vacíos que se resuelven y los inapropiados usos que se mencionan para el instrumento. Nos interesa en esta reflexión advertir cómo la institucionalidad que legitimiza las prácticas que se observan se construye y se sostiene en el tiempo, en términos teóricos, dado que allí radica la principal dificultad para realizar transformaciones.

\section{Institucionalismo}

El estudio de las instituciones, como restricciones para la toma de decisiones (Romero ${ }^{1}$ ) encuentra un segundo momento de reflexión a partir de un artículo publicado por March y Olsen $^{2}$ considerado seminal en esta etapa. Al decir de Vergara ${ }^{3}$ este artículo irrumpe en un momento en que la ciencia política está "dominada por el paradigma racional".

Las instituciones son entendidas como "reglas del juego" creadas por las personas, que determinan incentivos en el funcionamiento de las organizaciones en el ambiente político, social o económico. Representan constreñimientos creados para estructurar y ordenar el ambiente donde aquellas se desempeñan.

La siguiente lista de instituciones pertenece a Jepperson ${ }^{4}$, quien las pone como ejemplo 
para señalar lo que tienen en común: que son sistemas de producción o estructuras que permiten hacer algo:

- Matrimonio, Sexismo, Contrato, Salario, Saludo de mano, Seguro, Organización formal, Ejército, Ocupación académica, Presidencia, Vacaciones, Asistir a la universidad, Corporación, Motel, Disciplina académica, Votar.

Señala Jepperson ${ }^{5}$ que las instituciones son sistemas de programas o de gobierno socialmente construidos y reproducidos rutinariamente en las organizaciones, enfatizando que es arbitrario asimilar las instituciones con las organizaciones formales, como ocurre en la literatura.

Interesa al institucionalismo averiguar cómo los arreglos institucionales configuran, median y catalizan las elecciones. Está sugerido que las referencias individuales y categorías básicas del pensamiento, como la personalidad, la acción social, el Estado y la ciudadanía, son conformadas por fuerzas institucionales. Ahora bien, si bien son resultado de actividad humana, las instituciones no surgen deliberadamente. Son constructos que emergen de procedimientos rutinarios que se instalan imperceptiblemente como modos de hacer las cosas y van adquiriendo estatus de regla o norma para el buen funcionamiento.

Tres vertientes de pensamiento son elegibles para lo que se ha denominado nuevo institucionalismo: una aproximación económica, una desde las ciencias políticas y otra desde la sociología, siendo esta última la que ha marcado la teoría de las organizaciones (Powell y Di Maggio ${ }^{6}$ ). No obstante, los autores March y Olsen ${ }^{7}$, situados cerca de las ciencias políticas, exploran la utilidad de la toma de decisiones racionales, intentando balancear fenómenos políticos de carácter confrontacional con lo que denominan la dimensión institucional, que no se ajusta a los modelos de decisiones racionales, privilegiando mecanismos de formación de consensos y metas sociales colectivas. Para estos autores no es el individuo y sus preferencias la unidad de análisis, sino las reglas, normas y tradiciones existentes en las organizaciones.

En definitiva, siendo válido para todas las corrientes de pensamiento del nuevo institucionalismo, se parte de la idea central de que en las organizaciones no se toman decisiones racionales para optimizar recursos. Vergara $^{8}$ cita a Herbert
Simon, quien plantea que la idea de decisiones racionales en las organizaciones es irreal. Se afirma que sólo se toman decisiones que intentan ser satisfactorias-racionalidad limitada-, dado que no existe información ni tiempo para actuar racionalmente, habida cuenta del intrincado proceso de formación de preferencias (March y Olsen ${ }^{9}$ ) y la impredictibilidad de su permanencia; entonces las instituciones aparecen como elementos sustentantes del comportamiento de los agentes.

Producto de ello se ha ido poniendo creciente interés en el paisaje que rodea las decisiones, en el que se desenvuelven quienes las toman y surge la idea de la atención organizacional como recurso escaso. Es decir, la posibilidad de poner al servicio de todos los ámbitos de la organización la inteligencia para decidir acerca de cada proceso es impracticable y obliga a generar rutinas para liberar capacidad de atención organizacional, la que se reserva para situaciones especiales o imprevistas, principalmente en unidades de desempeño insatisfactorio. March y Olsen ${ }^{10}$ hacen referencia a lo que denominan el modelo de botes de basura, que implica que existe en las organizaciones una cartera de soluciones generadas en distintos momentos pero disponibles cuando un problema se genera -mientras más tiempo disponibles más probable su uso- y luego se aplican haciendo de la pertinencia un resultado fortuito.

De hecho, en su vertiente económica el nuevo institucionalismo nace como reacción a la idea de una racionalidad sin costos de transacción, lo que ha sido calificado como exceso de la economía neoclásica (Romero $\left.{ }^{11}\right)$. Entonces, las instituciones aparecen como mecanismos desarrollados para reducir costos de transacción, lo que en las organizaciones se refleja en rutinas que se repiten sistemáticamente y que explican comportamientos razonables. La capacidad de las rutinas para resolver situaciones que se presentarán desde el ambiente acaba por darles un carácter institucional. Hay quienes consideran a las instituciones como gustos congelados temporalmente. Al decir de North, citado por Powell y Di Maggio" "las instituciones son regularidades en interacciones repetitivas (...) costumbres y reglas que proporcionan un conjunto de incentivos y desincentivos para los individuos". Los economistas y teóricos de la elección pública consideran a las instituciones como provisionales en el camino a la solución de equilibrio. 
Las instituciones pueden persistir aun cuando no sean óptimas, en consideración a que los costos de transacción de su transformación pueden ser altos, en particular si los consensos políticos son bajos: la ideología y el Estado juegan un rol importante en mantener a las instituciones, de allí el interés del nuevo institucionalismo en la toma de decisiones políticas. Las leyes, por otro lado, eliminan gran parte de la inestabilidad. Los regímenes imperfectos sobreviven gracias a estos factores. Algunos de los costos hundidos más importantes que explican la persistencia de instituciones son cognitivos, es decir, los individuos no solo ven restringidas sus opciones de concebir alternativas, sino que las instituciones establecen los criterios a través de los cuales descubren sus preferencias.

Si bien hay acuerdo en que el cambio institucional tiene origen en las tensiones entre organizaciones y ambiente y que, aunque sea incrementalmente ${ }^{13}$, las instituciones cambian, las escuelas del nuevo institucionalismo muestran diferencias. Para los neoinstitucionalistas económicos -neoinstitucionalismo regulativo- las penalidades que derivan de los comportamientos inducen estabilidad y el cambio consiste en ajustes marginales a las reglas y en sanción. Los cambios en los precios relativos modifican los incentivos y los individuos intentan cambiar las reglas de acuerdo con sus intereses.

En el otro extremo, para el neoinstitucionalismo sociológico -cognitivo- los cambios acontecen por transformaciones culturales, es decir, con base en la adquisición de conocimiento de organizaciones e individuos. Esto implicaría que si algún procedimiento, curso de acción o rutina no está presente en la cultura organizacional, no es opción. Los actores son pasivos y las organizaciones se adaptan lenta pero eficazmente, sin darse cuenta, a cambios ambientales. De la idea de campos organizacionales como espacio consolidado en que las organizaciones están adaptadas a sus instituciones surge la idea del isomorfismo (Powell y Di Maggio ${ }^{14}$ ), referido al proceso de adaptación que una organización vive al momento de incorporarse en su campo, que por lo general corresponde a una determinada industria o rama del quehacer.

Al centro de esta reflexión se ubican March y Olsen ${ }^{15}$ más cercanos al nuevo institucionalismo de las ciencias políticas -neoinstitucionalismo normativo- quienes reconocen la cultura en la base de la estabilidad, pero también las reglas y mecanismos de sanción a quienes las trasgreden; es decir, habría un espacio para cierto ejercicio de racionalidad que permite explicar procesos de cambio.

Si se tiene entonces que la estabilidad y el comportamiento de los individuos en la organización encuentra explicación en la cultura y en las normas, es interesante pensar cómo es que las rutinas organizacionales que se crean para atender las cuestiones cotidianas -lógica de la atención organizacional-y que son constitutivas de reglas, convenciones y normas y luego de tradiciones y mitos en la organización -prácticas que se dan por hecho-, configuran finalmente la cultura. Esta cultura representa el marco referencial que permite discriminar acerca de la relevancia de determinados asuntos y otorgar significado a la acción.

\section{Isomorfismo}

Jepperson ${ }^{16}$ piensa que son posibles grados de institucionalización a partir de la vulnerabilidad relativa de la organización a la intervención social. Es decir, mientras más institucionalizada una organización -o isomorfizada, siguiendo a Powell ${ }^{17}-$, menos vulnerable. El mismo autor distingue cuatro tipos de cambio: i) la formación institucional; ii) el desarrollo institucional; iii) la desinstitucionalización y iv) la reinstitucionalización, distinguiendo a la primera como un output de la entropía social, así como a la desinstitucionalización como un retorno a la misma. En cuanto a la reinstitucionalización, el autor da como ejemplo a las religiones occidentales en tanto transformación institucional en el tiempo, a raíz de una fuerza social persistente. El desarrollo institucional representaría la continuidad.

Argumentos de equilibrio evolutivo se han esgrimido para sostener que las instituciones y reglas sobrevivientes serían óptimas, en un contexto con recursos escasos. Las reglas, en una experiencia acumulativa, se tornarían inteligentes. Pero es sabido en la teoría de la evolución de las especies, que sobrevivientes tendieron a la extinción, por lo que, al decir de March y Olsen ${ }^{18}$ "el sentido común no está garantizado".

Meyer y Rowan ${ }^{19}$ examinan lo que denomi- 
nan Organizaciones Institucionalizadas, haciendo referencia a la estructura formal como mito y ceremonia. Los mitos basan su legitimidad, al decir de los autores, en el supuesto de que son racionalmente efectivos - por ejemplo, el conocimiento experto- $y$ en que responden a mandatos legales. El orden legal racional determina que las reglas y procedimientos y el personal racionalizados sean en la práctica requisitos institucionales.

Muchas organizaciones buscan privilegios legales con las autoridades públicas o intentan construir sus propios objetivos dentro de la sociedad en forma directa, como reglas institucionales. En muchos casos organizaciones poderosas pueden obligar a los rivales a operar con reglas del juego que han sido instaladas por ellas mismas, perpetuando formas que se han convertido en instituciones. También ocurre que organizaciones que se mueven en ambientes competitivos tratan de ocupar espacios en tradiciones culturales de la sociedad buscando protección oficial.

A propósito de instituciones como arreglos corporativos, redes de políticas que vinculan grupos económicos con burocracia estatal y estructura de partidos políticos, una experiencia reciente dice relación con la crisis económica definida por Johnson ${ }^{20}$, ex economista Jefe del Fondo Monetario Internacional, como "golpe silencioso", a propósito de cómo la élite financiera de Wall Street promovió sistemáticamente modificaciones institucionales que influyeron de manera claramente inconveniente, hasta producir niveles de laxitud tales en las reglas del juego, que hicieron posible la crisis.

El isomorfismo promueve el uso de ceremonias que constituyen legitimidad. Mucho de lo que la organización hace con apariencia racional responde a la construcción de legitimidad social, a que no se dude de su conducta. Es decir, si no lo hacen, "carecen de explicaciones legitimadas aceptables acerca de sus actividades" (Meyer y Rowan ${ }^{21}$ ). En la práctica las instituciones racionalizadas crean mitos de estructura formal y ceremoniales determinantes de las organizaciones.

Ocurre que no importa que las escuelas eduquen o los hospitales curen a los pacientes, si cuentan con las estructuras y expertos, si dictan la cantidad de cursos habituales y realizan los procedimientos estándar que les permitirían acreditar formalmente frente a sistemas que su- puestamente les controlan, pero que se dedican a la conformidad ritual. Entonces, continuarán gozando de la buena voluntad social y obteniendo los recursos del gobierno. En ambientes institucionales complejos (Morin ${ }^{22}$; Tarride ${ }^{23}$ ) donde es difícil evaluar la eficiencia productiva y la eficacia, las organizaciones que se hacen isomorfas sobreviven. De hecho, evaluar resultados podría conducir a la ilegitimidad, socavando aspectos ceremoniales.

\section{Seguridad Social en Chile}

El sistema de seguridad social chileno, desde sus orígenes a la fecha, ha producido formación institucional. Las agencias que han constituido el sistema se han isomorfizado y han desplegado también sus estándares para instalarlos como reglas en procura de garantizar su sobrevivencia. Siguiendo a Pierson ${ }^{24}$, la acción del gobierno en la materia -las políticas- ha sido determinante del comportamiento de los actores y de la generación de grupos de interés organizados en función de los constreñimientos emanados de la primera, mismos actores que después influirán sobre la acción del gobierno, como en un "círculo virtuoso". El gobierno -la gobernanza del sistema- se desplaza desde lo puramente formal y establecido en normas, para situarse en un espacio social amplio (Figura 1).

Ha habido momentos de gran legitimidad del sistema y también otros momentos, como durante el régimen militar en que bajo condiciones de excepción se realizaron transformaciones relevantes al sistema a partir de su hipotética insolvencia, como ocurrió con las pensiones, sin que la legitimidad fuera un elemento indispensable. Hoy, hechos del pasado parecen abrirse paso nuevamente $\left(\right.$ Pierson $^{25}$ ) retomándose la idea de protección social, en un escenario que reposa en una mixtura compuesta por una variedad no necesariamente coherente de organizaciones e instituciones, como es el caso del sistema previsional de salud (Vergara ${ }^{26}$ ) y en particular el de las licencias médicas (Figura 1). Es decir, la idea de protección social trae consigo necesariamente la idea de cambio, donde lo institucionalizado operará como un conjunto de certezas vigentes.

El sistema de licencias médicas en Chile se desenvuelve en un marco institucional al que puede 


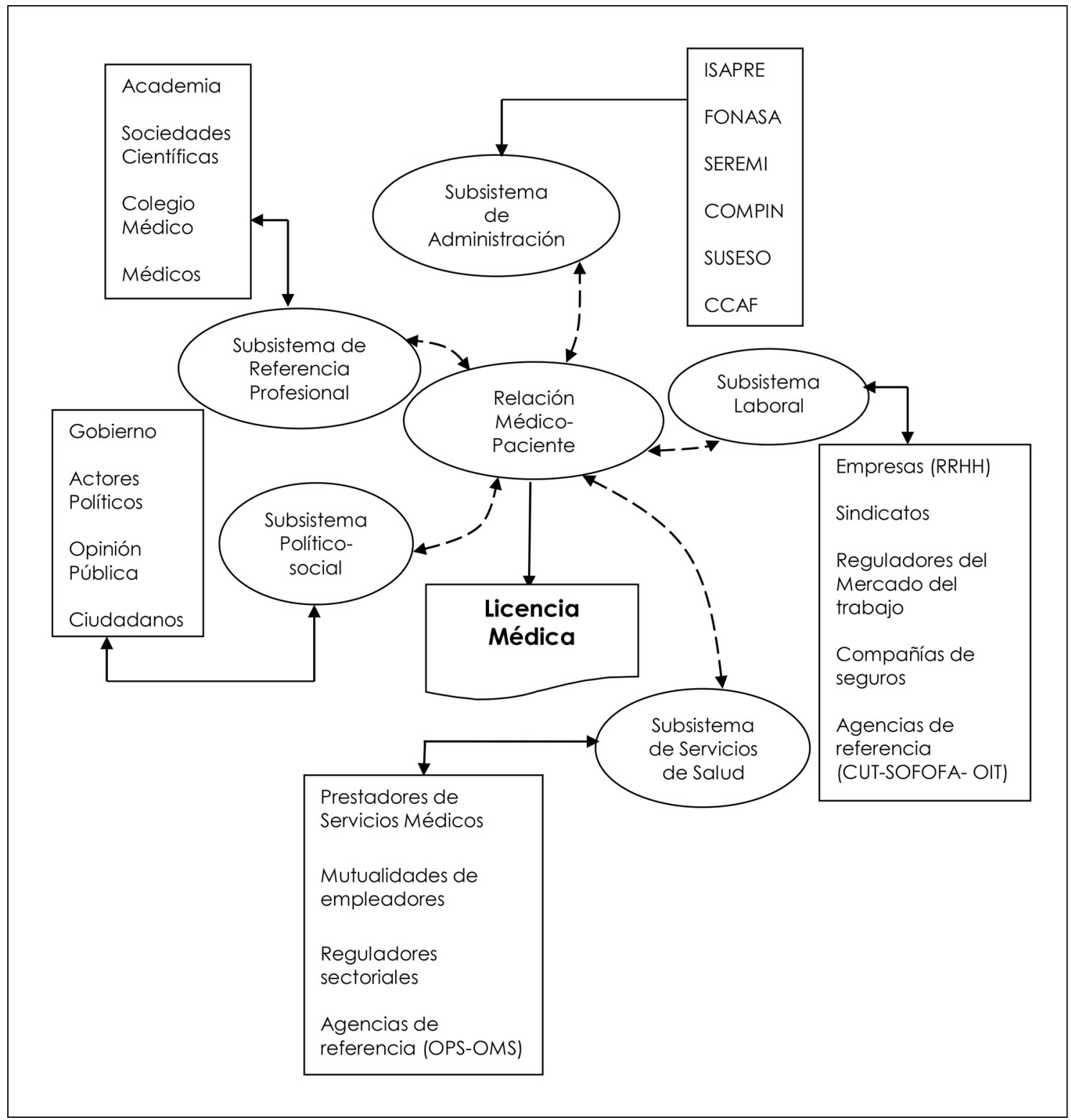

Figura 1. El sistema de Licencias Médicas (despliegue de actores, por subsistemas).

atribuirse, además, su problemática, a partir de incentivos que inducen variados comportamientos de actores que concurren formalmente a generar sus outputs.

En la Figura 1 el sistema ha sido representado en función de los subsistemas que lo componen, en cuanto grupos de actores relevantes para los efectos de comprender su situación y funciona- miento: el conjunto de stakeholders. La complejidad del cambio, al decir de Morin ${ }^{27}$ y Tarride ${ }^{28}$, se hace visible.

Por último, en la Tabla 1 se identifican quienes participan en la administración del sistema y el rol de cada uno en las etapas del proceso. Son 6 agencias: FONASA, ISAPRE, CCAF, COMPIN, SEREMI Y SUSESO. 
Tabla 1. Administración del sistema de Licencias Médicas

\begin{tabular}{|c|c|c|c|c|c|}
\hline Sistema previsional & Recaudación & $\begin{array}{l}\text { Contraloría de } \\
\text { Licencias Médicas }\end{array}$ & Pago & $\begin{array}{l}\text { Apelación } \\
\text { Primera } \\
\text { Instancia }\end{array}$ & $\begin{array}{l}\text { Apelación } \\
\text { Segunda } \\
\text { Instancia }\end{array}$ \\
\hline $\begin{array}{l}\text { Fondo Nacional de Salud } \\
\text { (FONASA) }\end{array}$ & FONASA & $\begin{array}{l}\text { Comisión de Medicina } \\
\text { Preventiva e Invalidez } \\
\text { (COMPIN) de la Secretaría } \\
\text { Regional Ministerial de } \\
\text { Salud (SEREMI) }\end{array}$ & $\begin{array}{l}\text { FONASA } \\
\text { vía } \\
\text { COMPIN }\end{array}$ & $\begin{array}{l}\text { COMPIN } \\
\text { (SEREMI) }\end{array}$ & $\begin{array}{l}\text { Superintendencia } \\
\text { de Seguridad } \\
\text { Social (SUSESO) }\end{array}$ \\
\hline $\begin{array}{l}\text { FONASA y Cajas de } \\
\text { Compensación (CCAF) }\end{array}$ & CCAF & $\begin{array}{l}\text { COMPIN } \\
\text { (SEREMI) }\end{array}$ & $\begin{array}{l}\text { FONASA } \\
\text { vía CCAF }\end{array}$ & $\begin{array}{l}\text { COMPIN } \\
\text { (SEREMI) }\end{array}$ & SUSESO \\
\hline $\begin{array}{l}\text { Instituciones de Salud } \\
\text { Previsional (ISAPRE) y CCAF }\end{array}$ & CCAF & ISAPRE & ISAPRE & $\begin{array}{l}\text { COMPIN } \\
\text { (SEREMI) }\end{array}$ & SUSESO \\
\hline ISAPRE & ISAPRE & ISAPRE & ISAPRE & $\begin{array}{l}\text { COMPIN } \\
\text { (SEREMI) }\end{array}$ & SUSESO \\
\hline
\end{tabular}

Fuente: Superintendencia de Salud, 2006 y elaboración complementaria propia.

\section{Referencias}

1. Romero J. Estudio Introductorio: Los nuevos institucionalismos, sus diferencias, sus cercanías. Powell, W. \& Di Maggio, P. (compiladores). El Nuevo Institucionalismo en el Análisis Organizacional: Introducción. Serie Nuevas Lecturas de Política y Gobierno. Fondo de Cultura Económica. México. 1999.

2. March J, Olsen J. The New Institucionalism: Organizational Factors in Political Life. The American Political Science Review 1984; 78: 734-9.

3. Vergara R. Estudio Introductorio en March J. \& Olsen J. El Redescubrimiento de las Organizaciones: La Base Organizativa de la Política. Serie Nuevas Lecturas de Política y Gobierno. Fondo de Cultura Económica. México. 1997.

4. Jepperson R. Instituciones, Efectos Institucionales e Institucionalismo. Capítulo V. Powell W. \& Di Maggio P. (compiladores) El Nuevo Institucionalismo en el Análisis Organizacional: Introducción. Serie Nuevas Lecturas de Política y Gobierno. Fondo de Cultura Económica. México. 1999.

5. Jepperson R. Instituciones, Efectos Institucionales e Institucionalismo. Capítulo V. Powell W. \& Di Maggio P. (compiladores) El Nuevo Institucionalismo en el Análisis Organizacional: Introducción. Serie Nuevas Lecturas de Política y Gobierno. Fondo de Cultura Económica. México. 1999.

6. Powell, W. \& Di Maggio, P. El Nuevo Institucionalismo en el Análisis Organizacional: Introducción. Powell, W. \& Di Maggio, P. (compiladores) Serie Nuevas Lecturas de Política y Gobierno. Fondo de Cultura Económica. México. 1999.

7. March J, Olsen J. El Redescubrimiento de las Organizaciones: La Base Organizativa de la Política. Serie Nuevas Lecturas de Política y Gobierno. Colegio Nacional de Ciencias Políticas y Administración Pública, A. C., Universidad Autónoma de Sinaloa y Fondo de Cultura Económica. México. 1997.

8. Vergara R. Estudio Introductorio en March, J. \& Olsen, J. El Redescubrimiento de las Organizaciones: La Base Organizativa de la Política. Serie Nuevas Lecturas de Política y Gobierno. Fondo de Cultura Económica. México. 1997.

9. March J, Olsen J. The New Institucionalism: Organizational Factors in Political Life. The American Political Science Review 1984; 78: 734-49.

10. March J, Olsen J. El Redescubrimiento de las Organizaciones: La Base Organizativa de la Política. Serie Nuevas Lecturas de Política y Gobierno. Colegio Nacional de Ciencias Políticas y Administración Pública, A. C., Universidad Autónoma de Sinaloa y Fondo de Cultura Económica. México. 1997.

11. Romero J. Estudio Introductorio: Los nuevos institucionalismos, sus diferencias, sus cercanías. Powell, W. \& Di Maggio, P. (compiladores). El Nuevo Institucionalismo en el Análisis Organizacional: Introducción. Serie Nuevas Lecturas de Política y Gobierno. Fondo de Cultura Económica. México. 1999.

12. Powell W, Di Maggio, P. El Nuevo Institucionalismo en el Análisis Organizacional: Introducción. Powell, W. \& Di Maggio, P. (compiladores) Serie Nuevas Lecturas 
de Política y Gobierno. Fondo de Cultura Económica. México. 1999.

13. Lindblom C. Still Muddling, Not Yet Through. Public Administration Review 1979; 39 (6): 517-26.

14. Powell W, Di Maggio P. El Nuevo Institucionalismo en el Análisis Organizacional: Introducción. Powell, W. \& Di Maggio, P. (compiladores) Serie Nuevas Lecturas de Política y Gobierno. Fondo de Cultura Económica. México. 1999.

15. March J, Olsen, J. El Redescubrimiento de las Organizaciones: La Base Organizativa de la Política. Serie Nuevas Lecturas de Política y Gobierno. Colegio Nacional de Ciencias Políticas y Administración Pública, A. C., Universidad Autónoma de Sinaloa y Fondo de Cultura Económica. México. 1997.

16. Jepperson R. Instituciones, Efectos Institucionales e Institucionalismo. Capítulo V. Powell, W. \& Di Maggio, P. (compiladores) El Nuevo Institucionalismo en el Análisis Organizacional: Introducción. Serie Nuevas Lecturas de Política y Gobierno. Fondo de Cultura Económica. México. 1999.

17. Powell W, Di Maggio P. El Nuevo Institucionalismo en el Análisis Organizacional: Introducción. Powell, W. \& Di Maggio, P. (compiladores) Serie Nuevas Lecturas de Política y Gobierno. Fondo de Cultura Económica. México. 1999.

18. March J, Olsen J. The New Institucionalism: Organiza- tional Factors in Political Life. The American Political Science Review 1984; 78: 734-49.

19. Meyer J, Rowan, B. Organizaciones Institucionalizadas: La Estructura Formal como Mito y Ceremonia. Capítulo I. Powell, W. \& Di Maggio, P. (compiladores) Serie Nuevas Lecturas de Política y Gobierno. Fondo de Cultura Económica. México. 1999.

20. Johnson S. The quiet Coup. The Atlantic Online. The Atlantic Monthly. May 2009.

21. Johnson S. The quiet Coup. The Atlantic Online. The Atlantic Monthly. May 2009.

22. Morin E. Introducción al pensamiento complejo. Edtorial Gedisa. Barcelona. 1997.

23. Tarride M. Salud Pública, una Complejidad Anunciada. Editorial Universidad de Santiago de Chile. 2004.

24. Pierson P. When Effect Becomes Cause: Policy Feedback and Political Change. World Politics 1993; 45 (4): 595628.

25. Pierson P. Three Worlds of Welfare State Research. Comparative Political Studies 2000; 33: 791-821.

26. Vergara, M. La Dicotomía Estado Mercado en el Sector de la Salud en Chile. Estudios Sociales, de la Corporación de Promoción Universitaria, №108, Semestre 2. 2001.

27. Morin E. Introducción al pensamiento complejo. Edtorial Gedisa. Barcelona. 1997.

28. Tarride, M. Salud Pública, una Complejidad Anunciada. Editorial Universidad de Santiago de Chile. 2004. 